\title{
Mullerian ductal anomalies and its outcome
}

\section{Rupa C. Vyas, Ashleta M. Moghariya*, Sapana R. Shah, Purvi M. Parikh, Prachi M. Shelat}

Department of Obstetrics and Gynecology, Smt. NHL Medical College and VS Hospital, Ahmedabad, Gujarat, India

Received: 29 September 2018

Accepted: 06 December 2018

\section{*Correspondence:}

Dr. Ashleta M. Moghariya,

E-mail: ashipatel145.ap5@gmail.com

Copyright: () the author(s), publisher and licensee Medip Academy. This is an open-access article distributed under the terms of the Creative Commons Attribution Non-Commercial License, which permits unrestricted non-commercial use, distribution, and reproduction in any medium, provided the original work is properly cited.

\section{ABSTRACT}

Background: The aim is to study various investigative modalities to diagnose Mullerian anomalies and to evaluate the reproductive outcome that occurs as a result of malformation of genital tract.

Methods: A prospective study of reproductive anomalies and its outcome was performed by using data from women with congenital anomalies attended in OPD either with complains or for operative treatment or incidental diagnosis during caesarean section, manual removal of placenta, during laparoscopy or laparotomy at tertiary care center. Total 70 women with different types of congenital anomalies were included in study. Out of them gynecological cases (27) were diagnosed on basis of clinical examination and other diagnostic aids while Mullerian anomalies in obstetric cases (43) were observed and their outcomes were studied.

Results: Most common utero-vaginal anomaly seen in present study was septate uterus with $18(25.7 \%)$ cases, followed by bicornuate uterus with $13(18.6 \%)$ cases. Most common presenting symptom is primary amenorrhea 21 (30\%) followed by cyclical abdominal pain 11 (15.7). HSG, USG are the primary tools to detect genital tract anomalies. Surgical correction was required in $47.1 \%$ patients.

Conclusions: Present study shows prevalence of congenital malformation of female reproductive tract is $0.17 \%$ at our tertiary care center. Utero-vaginal anomalies are a morphologically diverse group of developmental disorders. Establishing an accurate diagnosis is essential for planning treatment and management strategies. The surgical approach for correction of utero-vaginal anomalies is specific to the type of malformation and may vary in a specific group.

Keywords: Congenital anomalies, MRI, Reproductive function, USG

\section{INTRODUCTION}

Congenital anomalies of the female genital tract are among the most fascinating disorders encountered by the obstetrician. Aberration in the development of Mullerian ducts result in abnormalities of internal reproductive structures as well as ambiguity of the external genitalia. These abnormalities are often caused by errors in organogenesis, but other etiologies including deficiencies in steroidogenesis, receptor defects and genetic abnormalities are also involved. ${ }^{1}$ Normal development of the female genital tract involves a series of complex processes which includes differentiation, migration, fusion and canalization of Mullerian system. ${ }^{2}$ Most Mullerian ductal anomalies are associated with functioning ovaries and age appropriate external genitalia. Congenital malformations of genital tract occur due to imperfect or incomplete development of Mullerian duct or urogenital sinus. The Mullerian ducts are primordial anlage of the female reproductive tract. During fatal life abnormality in formation, fusion or resorption of Mullerian ducts results in congenital uterine anomalies and they are present in $1-10 \%$ of unselected population, $2-8 \%$ of infertile women and $5-30 \%$ of 
women with history of miscarriage. ${ }^{3-10}$ This present study includes malformations that affect the development and morphology of fallopian tubes, uterus and vagina with or without associated ovarian, urinary, skeletal or other organ malformation. Because of the wide variations in clinical presentations, Mullerian duct anomalies may be difficult to diagnose. But various investigations like HSG, TVS, 3-D USG, laparo-hysteroscopy, and MRI helps to diagnose more cases nowadays. ${ }^{11}$ After an accurate diagnosis is rendered, many treatment options exist, and they are usually tailored to the specific uterovaginal anomaly.

The aim of the study was to understand embryology of female genital tract, to observe the prevalence of congenital anomalies of genital tract in our population, their clinical implications, impact on reproductive outcomes, complications in pregnancy and to study various investigative modalities to diagnose the congenital anomalies of female genital tract.

\section{METHODS}

A prospective study was performed at our institute to observe the congenital anomalies of female genital tract in our population and their clinical implication. The study period was from July 2014 to July 2018. Total 70 women with different types of congenital anomalies were detected. Women with congenital anomalies attended our department either with complains like primary amenorrhea, cyclical abdominal pain, dyspareunia, primary infertility and recurrent abortion and women with incidental diagnosis during ultrasound, caesarean section, manual removal of placenta, during laparoscopy or laparotomy were included. In most of the gynecological cases diagnosis was made on clinical ground and was confirmed by other diagnostic aids like ultrasound, diagnostic laparoscopy, and hysteroscopy.

\section{Inclusion criteria}

- Primary amenorrhea

- Primary infertility

- Recurrent abortion

- Recurrent preterm delivery

- Women with IVF treatment.

In present study patients were divided into two groups for convenient study:

Group A: Gynecological cases with congenital anomaly of female genital tract.

All women underwent clinical examination and some needed examination under anaesthesia. USG was done in every patient to assess the uterus, any other pelvic pathology and to exclude the renal abnormalities. Patients underwent different investigations like HSG ( $n=9)$,
Hysteroscopy and laparoscopy $(n=5)$, Laparoscopy $(n=1)$, MRI ( $n=0)$ according to need as diagnostic modalities.

Group B: Obstetric cases with congenital anomalies of female genital tract.

All such patients were observed, and their outcomes were studied.

\section{RESULTS}

In present study, majority of the congenital anomalies related to gynecological cases were observed in mean age group 19.03 years. While maximum number of cases of Group B were observed in mean maternal age of 24.5 years.

It was found that septate uterus $(25.7 \%)$ is the commonest uterine anomaly followed by bicornuate uterus (18.5\%) as showed in Table 1.

Table 1: Different anomalies of female genital tract.

\begin{tabular}{|l|l|l|l|}
\hline $\begin{array}{l}\text { Type of anomaly } \\
\begin{array}{l}\text { Imperforate } \\
\text { hymen }\end{array}\end{array}$ & 8 & - & $8(11.4)$ \\
\hline $\begin{array}{l}\text { Septate uterus } \\
\text { Vaginal Septum }\end{array}$ & 5 & 13 & $18(25.7)$ \\
\hline $\begin{array}{l}\text { Cervical } \\
\text { agenesis }\end{array}$ & 1 & 2 & $11(15.7)$ \\
\hline $\begin{array}{l}\text { Bicornuate } \\
\text { uterus }\end{array}$ & - & 13 & $1(1.4)$ \\
\hline \begin{tabular}{l|l|l|} 
Arcuate uterus \\
Unicornuate uterus
\end{tabular} & - & 5 & $5(7.1)$ \\
\hline $\begin{array}{l}\text { With horn } \\
\text { Without horn }\end{array}$ & - & 4 & $10(14.3)$ \\
\hline Didelphys uterus & - & 3 & $3(4.3)$ \\
\hline
\end{tabular}

Out of 18 cases of septate uterus, 13 cases were presented during pregnancy and remaining 5 were presented with primary or secondary infertility, which were surgically corrected.

In early adolescent age group, the most common anomalies were transverse vaginal septum and imperforate hymen in the present study. Only 1 case of MRKH syndrome and 1 case of cervical agenesis and vaginal atresia was found.

In present study, 2 cases of unicornuate uterus without rudimentary horn with absent ipsilateral kidney were found and they were confirmed during LSCS.Four patients with rudimentary horn pregnancy presented with acute abdominal pain. Out of them 3 cases presented with ruptured rudimentary horn pregnancy and hemoperitoneum and required emergency laparotomy. Three patients were presented with history of recurrent abortion. All of them had septate uterus, which was diagnosed by USG. 
Two patients with c/o dyspareunia had isolated longitudinal vaginal septum. In 1 case, longitudinal vaginal septum was diagnosed while $\mathrm{D}$ and $\mathrm{E}$, and in other it was diagnosed in first stage of labour.

In present study, 11 cases of missed abortion had congenital utero-vaginal anomalies, out of them 4 had septate uterus, 6 had bicornuate uterus and remaining 1 had isolated longitudinal vaginal septum. First trimester USG helps to diagnosis associated congenital uterovaginal anomalies and helps in proceeding for $\mathrm{D}$ and $\mathrm{E}$ under USG guidance and avoids complications.

Table 2: Various modalities of diagnosis.

\begin{tabular}{|l|l|}
\hline Group A & No. of patients \\
\hline Hysterosalpingograpy & 9 \\
\hline Ultrasonography & 27 \\
\hline MRI & 0 \\
\hline Hystero-laparoscopy & 5 \\
\hline Laparoscopy & 1 \\
\hline
\end{tabular}

In present study, laparoscopy was carried out in one case of MRKH syndrome to confirm USG diagnosis and simultaneously laparoscopic Davydov's technique of vaginoplasty was performed. Same way, Hysterolaparoscopy was carried out in 5 cases of septate uterus to confirm ultrasound diagnosis and for hysteroscopic resection of the septum.

Table 3: Accidental diagnosis during surgery.

\begin{tabular}{|c|c|c|c|}
\hline Group B & LSCS & $\begin{array}{l}\text { Manual } \\
\text { removal of } \\
\text { placenta }\end{array}$ & $\begin{array}{l}\text { Normal } \\
\text { labour }\end{array}$ \\
\hline Bicornuate uterus & 6 & 1 & - \\
\hline Arcuate uterus & 5 & - & - \\
\hline Septate uterus & 4 & 5 & - \\
\hline Didelphys uterus & 2 & - & - \\
\hline $\begin{array}{l}\text { Unicornuate uterus } \\
\text { with horn }\end{array}$ & - & - & - \\
\hline $\begin{array}{l}\text { Unicornuate uterus } \\
\text { without horn }\end{array}$ & 3 & - & - \\
\hline $\begin{array}{l}\text { Isolated } \\
\text { longitudinal } \\
\text { vaginal septum }\end{array}$ & & - & 1 \\
\hline
\end{tabular}

Present study showed accidental diagnosis of congenital utero-vaginal anomalies in caesarean section in 20 cases. One case with didelphys uterus required LSCS for fetal distress. Six cases required MRP for retained placenta and there was an accidental diagnosis of septate uterus in 5 cases and bicornuate uterus in 1 case. One case with isolated longitudinal vaginal septum was diagnosed during early labour and then excised.

Present study showed accidental diagnosis of congenital utero-vaginal anomalies in 20 cases during caesarean section. Out of 20 women, 6 had bicornuate uterus, 5 had arcuate uterus, 4 had septate, 3 had unicornuate uterus without rudimentary horn, and 2 had didelphys uterus which was mentioned in Table 3 . All 3 cases delivered vaginally.

Cases of septate and bicornuate uterus with missed abortion diagnosed during first trimester may require surgical correction of genital malformation in future if there is recurrent abortion. In present study 2 cases of Mayer Rokytansky Hauser Syndrome have undergone vaginoplasty which were diagnosed by MRI. ${ }^{10}$

In present study, there were 9 cases of transverse vaginal septum. Out of them 3 had high and 2 had mid transverse vaginal septum. Excision of vaginal septum, drainage of heamatocolpos and hematometra and approximation of upper and lower vaginal edges was done. Remaining 4 had low transverse vaginal septum which required excision. Regular vaginal dilatation was required in all cases.

Only 1 case of high transverse vaginal septal excision developed post-operative vaginal stricture which required repeated surgeries to release fibrosis and vaginal dilation for long time.

One case with vaginal atresia was planned for Mc Indoe vaginoplasty, per operatively cervical agenesis was also found. It was difficult to drain hematometra through dense fibrous tissue between uterine cavity and vagina. Abdominal hysterectomy (with prior consent) was performed to remove functional uterus along with vaginoplasty. In 8 patient hymenotomy was performed in imperforate hymen. They had started normal menstruation. Hysteroscopic uterine septal resection was done in 5 patients. One patient had complete septum up to so. Cervical septum was cut with scissor and uterine septum was cut with resectoscope. One patient conceived after 5 months of surgery and required isthmic encerclage after 14 weeks of gestation

\section{DISCUSSION}

In present study, most common age group for congenital anomalies of GROUP A is between 16-20 years, while the most common age group for congenital anomalies of GROUP B is between 21-25 years which is comparable to study done by Meiling Hua Et Al12 who reported mean maternal age of patients around 29 years. 28 patients of group B were delivered either vaginally or by caesarean section, out of them $60.8 \%$ had cephalic presentation, $25 \%$ had breech presentation and $14.3 \%$ had a transverse lie which is comparable to Meiling hua et al, where breech was observed in $23.6 \%$ cases. Primary amenorrhea, abdominal pain and hematocolpos are most common presenting symptoms seen in patient with transverse vaginal septum and imperforate hymen which was also observed by Ben Temime R et al. ${ }^{12,13}$ Mullerian duct anomalies can be diagnosed by clinical examination, by using HSG, 2D-USG, 3D USG, MRI and hystero- 
laparoscopy. Bermejo et al, reported 3D ultrasound as a useful complementary tool than $2 \mathrm{D}$ ultrasound in the diagnosis of uterine malformations. In doubtful cases, MRI should be performed, particularly for the assessment of the cervix and vagina. ${ }^{14}$ At present combined use of laparoscopy and hysteroscopy is the gold standard for diagnosis of septate uterus.

Minto et al, has also reported ultrasound as the initial investigation for all patients with simple Mullerian anomalies. $^{15}$ The Patient with congenital utero-vaginal malformation had significant higher rates of preterm delivery (21.4\%) which is comparable with study conducted by Zhang et al, where preterm delivery rate was $19.8 \% .^{16}$

The commonest anomaly seen in present study is septate uterus followed by bicornuate uterus in reproductive age group, while in adolescent girls' imperforate hymen and transverse vaginal septum are most common. Grimbizis Gf et al, also reported septate uterus $(35 \%)$ as the most common utero-vaginal anomaly followed by bicornuate uterus (25\%). ${ }^{17}$ Utero genital malformation detected during LSCS, MRP, and normal labour did not require surgical treatment. Cases of abortion with utero-genital malformation if present in future with recurrent abortion may require surgical correction. In present study $47.1 \%$ cases required surgical correction which was mentioned in Table 4 which was comparable to study conducted by Begun J et al. ${ }^{18}$ Restoration of normal uterine architecture and preservation of fertility are the goals of surgical treatment. However normal or near normal architecture cannot be always achieved.

Table 4: Treatment summary of congenital anomalies of genital tract.

\begin{tabular}{|l|l|}
\hline Treatment summary & Number $(\%)$ \\
\hline Surgical treatment required & $33(47.1)$ \\
\hline Treatment not required & $27(38.6)$ \\
\hline Treatment may be required in future & $10(14.3)$ \\
\hline Treatment refused & - \\
\hline Patient referred & - \\
\hline
\end{tabular}

\section{CONCLUSION}

Utero-vaginal anomalies are morphologically diverse group of developmental disorders that involve the internal female reproductive tract. Establishing an accurate diagnosis is essential for planning treatment and management strategies. The surgical approach for correction of utero vaginal anomalies is specific to the type of malformation and may vary in a specific group. For most surgical procedures, the critical test of the procedure's value is the patient's postoperative ability to have healthy sexual relation and achieve successful reproductive outcomes.

Funding: No funding sources Conflict of interest: None declared
Ethical approval: The study was approved by the Institutional Ethics Committee

\section{REFERENCES}

1. Strissel PL, Oppelt P, Cupisti S, Stiegler E, Beckman MW, Strike R. Assessment of pituitary and steroid hormones and member of the TGF-beta superfamily for ovarian function in patient with congenital uterus and vaginal aplasia (MRKH syndrome). Horm Res. 2009;41(5):408-13.

2. Amesse LS, Pfaff-Amesse T. Congenital anomalies of reproductive tract. In: Falcone T, Hurd WW, eds. Clinical Reproductive Medicine and Surgery. $1^{\text {st }} \mathrm{ed}$. Mosby: New York, NY; 2007:171-190.

3. Moore KL, Persaud TV, Torchia MG. Before we are born: essentials of embryology and birth defects. Elsevier Health Sci; 2016.

4. Ashton D, Amin HK, Richart RM, Neuwirth RS. The incidence of asymptomatic uterine anomalies in women undergoing transcervical tubal sterilization. Obstet Gynecol. 1988;72(1):28-30.

5. Jurkovic D, Gruboeck K, Tailor A, Nicolaides KH. Ultrasound screening for congenital uterine anomalies. BJOG: An Int J Obstet Gynaecol. 1997;104(11):1320-1.

6. Raga F, Bauset C, Remohi J, Bonilla-Musoles F, Simón C, Pellicer A. Reproductive impact of congenital Müllerian anomalies. Human Reprod (Oxford, England). 1997;12(10):2277-81.

7. Simón C, Martinez L, Pardo F, Tortajada M, Pellicer A. Müllerian defects in women with normal reproductive outcome. Fertil Steril.1991;56(6):1192 3.

8. Acién P. Reproductive performance of women with uterine malformations. Human Reprod. 1993;8(1):122-6.

9. Godinjak Z, Idrizbegović E. Should diagnostic hysteroscopy be a routine procedure during diagnostic laparoscopy in infertile women?. Bosnian J Basic Med Sci. 2008;8(1):44.

10. Ghi T, Casadio P, Kuleva M, Perrone AM, Savelli L, Giunchi $S$, et al. Accuracy of three-dimensional ultrasound in diagnosis and classification of congenital uterine anomalies. Fertil Steril. 2009;92(2):808-13.

11. Troiano RN, McCarthy SM. Mullerian duct anomalies: imaging and clinical issues. Radiol. 2004;233(1):19-34.

12. Hua M, Odibo AO, Longman RE, Macones GA, Roehl KA, Cahill AG. Congenital uterine anomalies and adverse pregnancy outcomes. Am J Obstet Gynecol. 2011;205(6):558-e1.

13. Temime RB, Najar I, Chachia A, Attia L, Makhlouf T, Koubaa A. Hymenal imperforation: About 13 cases. Med Tunisia. 2010;88(3):168-71.

14. Bermejo C, Ten PM, Cantarero R, Diaz D, Pedregosa JP, Barrón E, et al. Three-dimensional ultrasound in the diagnosis of Müllerian duct anomalies and 
concordance with magnetic resonance imaging. Ultrasound Obstet Gynecol. 2010;35(5):593-601.

15. Minto CL, Hollings N, Hall-Craggs M, Creighton S. Magnetic resonance imaging in the assessment of complex Müllerian anomalies. BJOG: An Int J Obstet Gynaecol. 2001;108(8):791-7.

16. Zhang Y, Zhao YY, Jie Q. Obstetric outcome of women with uterine anomalies in China. Chin Med J. 2010;123(4):418-22.

17. Grimbizis GF, Gordts S, Di Spiezio Sardo A, Brucker S, De Angelis C, Gergolet M, et al. The ESHRE/ESGE consensus on the classification of female genital tract congenital anomalies. Human Reprod. 2013;28(8):2032-44.
18. Chatterji J, Alexander C, Jalais A. The Bengal diaspora: Rethink Muslim Migration. Routledge. 2015.

19. Strübbe EH, Willemsen WN, Lemmens JA, Thijn CJ, Rolland R. Mayer-Rokitansky-Küster-Hauser syndrome: distinction between two forms based on excretory urographic, sonographic, and laparoscopic findings. AJR. Am J Roentgenol. 1993;160(2):331-4.

Cite this article as: Vyas RC, Moghariya AM, Shah SR, Parikh PM, Shelat PM. Mullerian ductal anomalies and its outcome. Int J Reprod Contracept Obstet Gynecol 2019;8:440-4. 